\title{
Prediction of streamflow from the set of basins flowing into a coastal bay
}

\author{
A. DE LAVENNE ${ }^{1,2}$ \& C. CUDENNEC ${ }^{1,2}$ \\ 1 INRA, UMR1069, Sol Agro et hydrosystème Spatialisation, F-35000 Rennes, France \\ alban.delavenne@rennes.inra.fr \\ 2 AGROCAMPUS OUEST, UMR1069, Sol Agro et hydrosystème Spatialisation, F-35000 Rennes, France
}

\begin{abstract}
Many coastal basins of the Brittany peninsula (France) display a high level of nitrate pollution, nine of them highlighted by the European Commission since 2007, as causing algal blooms in several coastal bays. To precisely diagnose and solve this issue the fluxes of every contributing basin have to be considered. However, this faces a strong data-scarce situation as most of the basins are ungauged. In this context, we propose to transpose hydrological information from one gauged basin to neighbouring points of interest. The methodology uses a simple geomorphology-based transfer function on the gauged basin, which allows assessment of the net rainfall time series through the de-convolution of the gauged discharge series. This net rainfall is then transposed and convoluted on the ungauged basin using its own transfer function in order to estimate discharge. This approach enables the quantification of the whole volume of freshwater entering the controversial Saint-Brieuc Bay.
\end{abstract}

Key words ungauged basin; model; geomorphology-based model; regionalisation; inversion; transposition

\section{INTRODUCTION}

French coastal basins of Brittany are hydrological hot spots. A high level of nitrate pollution is responsible for green tide caused by algal blooms in several coastal bays. Nine coastal basins have been pointed out by the European Commission since 2007. The Saint-Brieuc Bay, presented in this paper, is one example. To precisely diagnose and solve this issue, the fluxes of every contributing basin have to be considered. However, most of the concerned basins are either poorly gauged or not gauged at the point of interest, which is, for such study, the river mouth. In this context, the proposed solution is to transpose hydrological measures from gauged basins to ungauged basins. Based on geomorphology-based modelling, this objective is achieved by estimating the net rainfall of the gauged basins. Benefiting from the scale independency of this variable, the latter is transposed to an ungauged basin in order to simulate the hydrograph therein. Taking advantage of the available monitoring stations in the studied area, this work aims at estimating the total fresh water flowing into the bay and the relative contribution of each coastal basin.

\section{MATERIALS AND METHODS}

\section{Studied catchments and data}

Four main basins flow into the Saint-Brieuc Bay (Fig. 1): Ic (point 1282, $79 \mathrm{~km}^{2}$ ), Goët (point 1279, $194 \mathrm{~km}^{2}$ ), Gouessant (point 1274, $242 \mathrm{~km}^{2}$ ) and Urne (point 1276, $40 \mathrm{~km}^{2}$ ) rivers. Many other small basins also contribute to the inflow to the bay. All those basins are located on the Armorican bedrock with a high drainage density, few aquifers and a fast response to rainfall. The west part (Gouët, Ic) is topographically characterised by deeper valleys compared to the east part (Gouessant).

This study focused on streamflow estimation of the freshwater flowing into the bay. The rivers are not gauged at their mouth point but at some upstream sites. For this reason, the study faces the issue of streamflow prediction of ungauged basins (Hrachowitz et al. 2013). The methodology is based on hydrograph transposition from one gauged basin to an ungauged basin. Those streamflow estimations aim to serve the quantification of the hydrogeochemistry of the bay, as most of its basins are subject to green tide caused by algal bloom.

In order to estimate the bay's freshwater inflow, every river flowing into the bay is taken into account. Discharge is estimated at the rivers' mouth point, which represents 21 truly ungauged points of interest. Streamflow at those points will be estimated using five monitoring stations of 


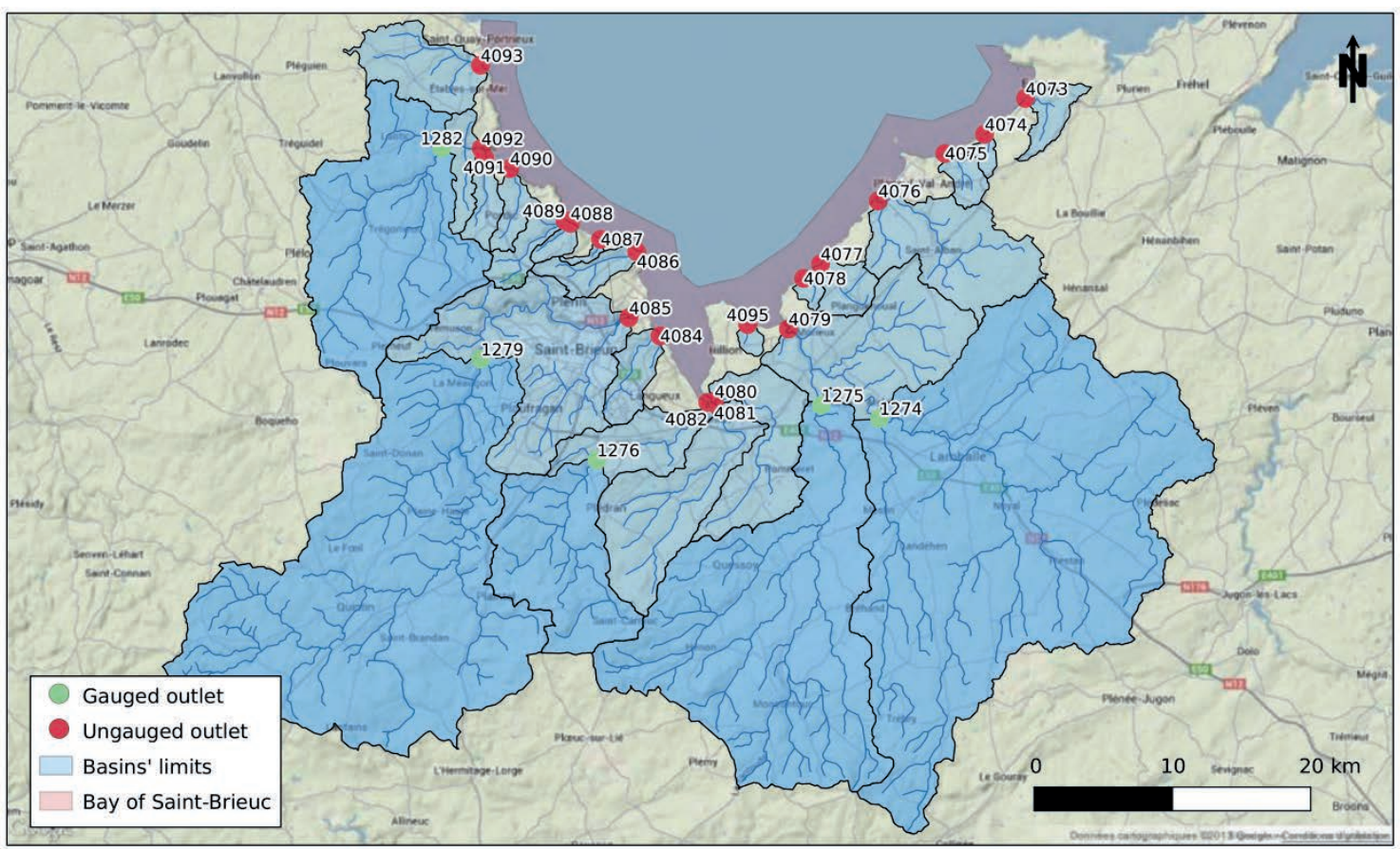

Fig. 1 Saint-Brieuc Bay with gauged and ungauged basins' outlets named by their identifying number (ID). Background map 2013 CGoogle.

the French Banque HYDRO database (www.hydro.eaufrance.fr). Runoff measurements are extracted at a variable time step and converted to a one hour time step. Simulations are performed at one hour time step.

\section{Modelling framework}

The modelling approach is focused on a geomorphometry-based transfer function across the network, which is distinguished from processes over the hillslopes (Robinson et al. 1995). This transfer function $T F$ is built from morphometric analysis of the river network. Using GRASS 6.4 completed by the toolkit of Jasiewicz and Metz (2011), the flow path length inside the network $L$ (so-called hydraulic length; Cudennec et al. 2004, Aouissi et al. 2013) is calculated throughout the basin from a digital elevation model (DEM). The DEM is at $50 \mathrm{~m}$ resolution, but is resampled at $25 \mathrm{~m}$ using bicubic sampling to increase the number of pixels inside small basins. The drainage modelling use the D8 algorithm and is forced toward the predefined river network given by the Sandre/BD CARTHAGE database. This is done using an algorithm based on the inverse distance to the network (Nagel et al. 2011). This allows the probability density function of hydraulic length $p d f(L)$ to be built for every basin (gauged or ungauged).

Assuming a linear transfer function through the river network (Beven and Wood 1993, Blöschl and Sivapalan 1995, Robinson et al. 1995, Giannoni et al. 2003, Nasri et al. 2004, Rodriguez et al. 2005, Cudennec 2007), the mean channel flow velocity is then needed to estimate the pdf of the water travel time $t$ through the river network $(p d f(t))$. Mean channel flow velocity was estimated from a sample of runoff events detected between 1990 and 2010. For gauged basins and each runoff event, channel flow velocity is calculated from the following equation:

$$
v_{i}=\frac{\bar{L}}{t_{i}}
$$

where $\bar{L}[\mathrm{~m}]$ is the mean hydraulic length of the basin and $t_{i}[\mathrm{~s}]$ the rise time of the runoff event $i$. The median of those velocities $v_{i}\left[\mathrm{~m} \cdot \mathrm{s}^{-1}\right]$ for each basin is then calculated to provide a constant velocity over time and space. 
This velocity estimation requires runoff measures and is therefore not suitable for ungauged basins. As a consequence velocity estimation of ungauged basins takes advantage of a relation between velocity inside the network and hydraulic length defined by de Lavenne (2013) over the Brittany region:

$$
\mathrm{V}=8.5947 \cdot 10^{-4} \cdot \bar{L}^{0.6146}
$$

The assessed unit hydrograph $p d f(t)=T F(t)$ is then used to estimate the discharge at the outlet $Q\left[\mathrm{~m}^{3} \cdot \mathrm{s}^{-1}\right]$ (step 1, Fig. 2). This calculation is made by the following convolution:

$$
Q(t)=S \cdot R_{n}(t) \times T F(t)
$$

where $t[\mathrm{~s}]$ is the time, $S\left[\mathrm{~m}^{2}\right]$ is the basin's surface area and $R_{n}[\mathrm{~m}]$ is the net rainfall.

Streamflow of ungauged basins is estimated by transposing net rainfall $R_{n}$ from a gauged to an ungauged basin. Net rainfall is defined as the depth of runoff provided by a basin's hillslope to its river network. Considering pairs of nested and neighbouring basins, the estimated net rainfall of one is used to represent the other. The time-series of discharge of the donor basin is de-convoluted by inverting its geomorphology-based transfer function to estimate the time-series of net rainfall (step 2, Fig. 2). The latter is then transposed to the receiver basin, where it can be re-convoluted with its own transfer function to predict the hydrograph therein (step 3, Fig. 2). By using only a basin's transfer function, production functions do not need to be estimated, thereby avoiding development of heterogeneous and highly nonlinear functions.

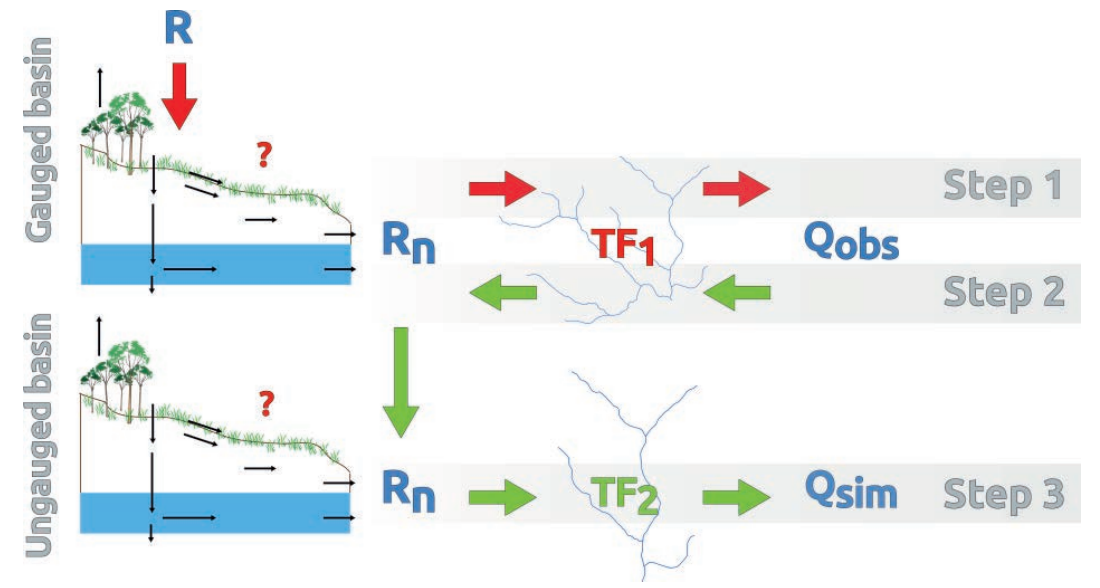

Fig. 2 Principle of hydrograph transposition (derived from de Lavenne et al. 2014).

De-convolution aims to determine the net rainfall vector series $R_{n}$ that best reconstitutes the observed outflow vector series $Q_{\text {obs }}$ according to the model given by equation (3). It is an inverse problem (Tarantola and Valette 1982, Menke 1989) that consists of minimizing the following:

$$
\left(\mathrm{Q}-\mathrm{Q}_{\mathrm{obs}}\right)^{T} \cdot\left(C_{Q}^{o b s}\right)^{-1} \cdot\left(Q-Q_{\text {obs }}\right)+\left(R_{n}-R_{n}^{a p}\right)^{T} \cdot\left(C_{R n}^{a p}\right)^{-1} \cdot\left(R_{n}-R_{n}^{a p}\right)
$$

where $R_{n}^{a p}$ is initializing a priori information about the vector sought, $C_{R n}^{a p}$ and $C_{Q}^{o b s}$ are covariance matrices for vectors $R_{n}^{a p}$ and $Q_{\mathrm{obs}}$, and superscript $T$ is the matrix transpose. $R_{n}^{a p}$ is estimated from specific discharge of $Q_{\text {obs }}$ delayed by its time of rise.

Based on previous studies (Boudhraâ 2007, Boudhraâ et al. 2006, 2009), and according to the inverse problems theory (Tarantola and Valette 1982, Menke 1989), a maximum likelihood solution can be obtained as follows:

$$
R_{n}=R_{n}^{a p}+C_{R n}^{a p} \cdot T F^{T} \cdot\left(T F \cdot C_{R n}^{a p} \cdot T F^{T}+C_{Q}^{o b s}\right)^{-1} \cdot\left(Q_{o b s}-T F \cdot R_{n}^{a p}\right)
$$

Performing this de-convolution is based on:

(a) assessing errors related to the $Q_{o b s}$ and $R_{n}^{a p}$ data that need to be parameterised, assuming that errors are 0 -centred Gauss-distributed, and 
(b) initialising via a priori assessment of the $R_{n}^{a p}$ parameters sought.

Covariance matrices need six different parameters to be estimated: Ad, Ap, Bd, Bp, Dd, Tp (see Cudennec (2000) and Boudhraâ (2007) for more details). Those parameters are fixed manually (Table 1) based on the results of de Lavenne (2013).

For a given receiver basin, the choice of a donor basin (Table 2) is made by applying the following rules:

(a) Priority is given to upstream stations draining the largest part of the receiver basin.

(b) When no upstream stations are available, the closest uninfluenced station is chosen to be the donor basin.

Indeed, the Goët River is influenced by the Saint-Barthélémy Dam (point 1279) where output discharge data are available. Because the approach uses runoff data directly as an input of hydrograph transposition, it was also possible to use this influenced discharged to consider the effect of the dam on the downstream part of the river.

Table 1 Parameter values used for inversing transfer function of every basin of Saint-Brieuc's Bay.

\begin{tabular}{llllll}
\hline $\mathrm{Ad}$ & $\mathrm{Ap}$ & $\mathrm{Bd}$ & $\mathrm{Bp}$ & $\mathrm{Dd}$ & $\mathrm{Tp}$ \\
\hline 0.01 & 0.9 & 0.01 & 0.001 & 1 & 20 \\
\hline
\end{tabular}

Table 2 Transpositions performed for modelling the total volume of freshwater flowing into the SaintBrieuc's Bay.

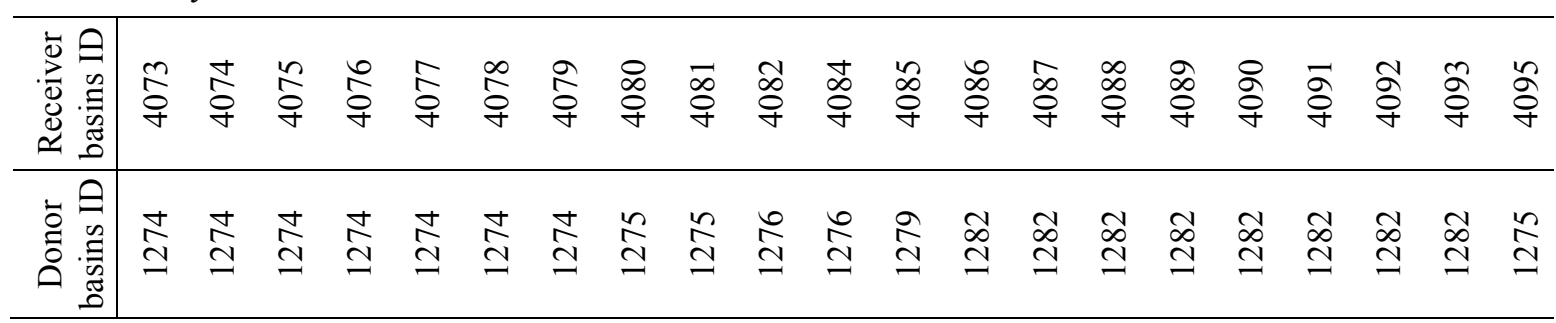

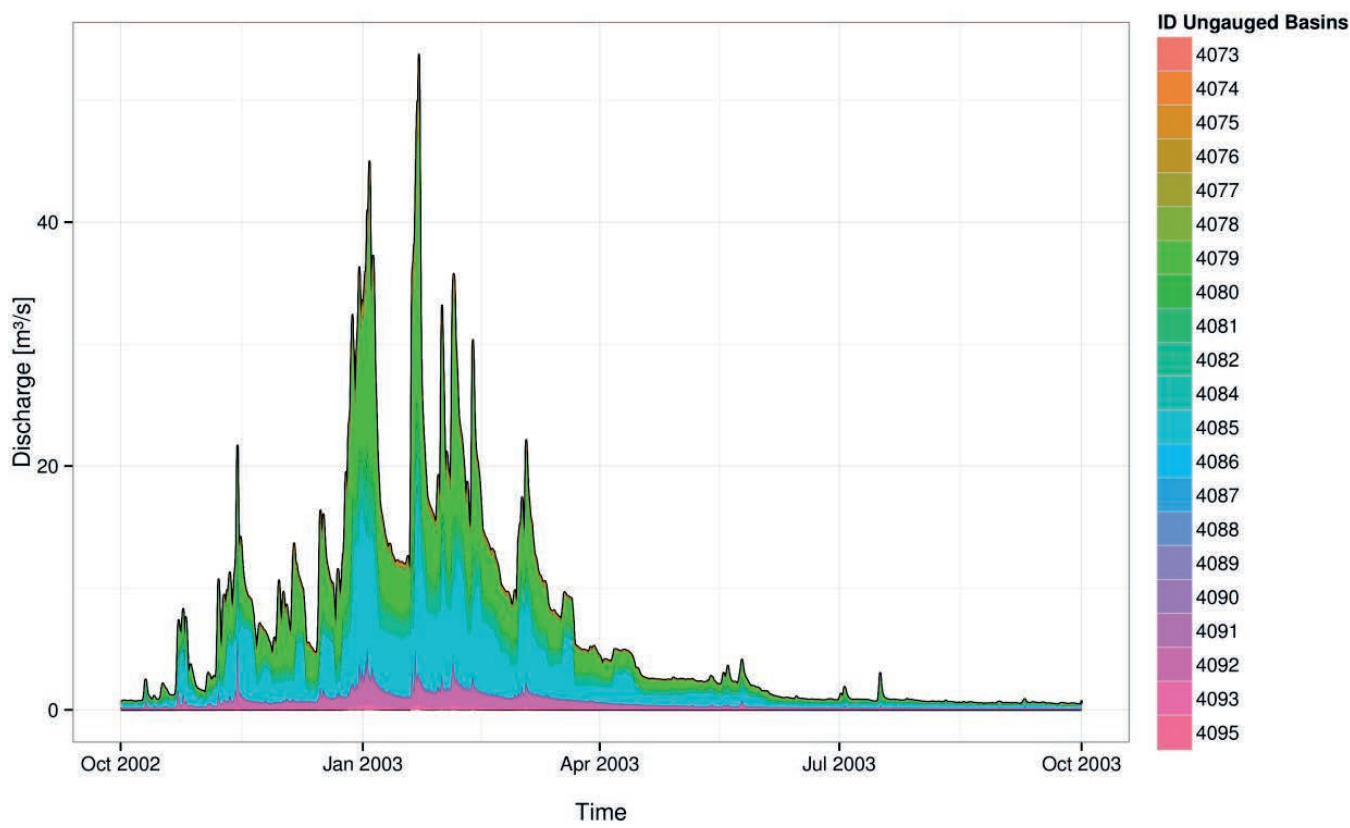

Fig. 3 Total freshwater flowing into the bay of Saint-Brieuc at hourly time steps. 


\section{RESULTS AND DISCUSSION}

\section{Freshwater flowing into the bay}

Once streamflow is simulated for each of the 21 ungauged basins, the total streamflow is estimated by summing the hydrograph of the 21 basins flowing into the bay. The resulting outflow is then able to characterise the absolute contribution (Fig. 3) and the relative contribution (Fig. 4) of every basin to the total freshwater entering the bay at an hourly time step.

The three main basins of the bay are highlighted, basins 4079 (Gouessant River), 4085 (Goët River) and 4092 (Ic River). It is seen that at an annual scale the relative contribution of each basin is not always constant throughout the year. For the hydrological year 2002-2003, it is seen that basin 4079 (Gouessant River) contributes more during the winter than during the summer. However, this conclusion was not confirmed for every year. Furthermore, unsteady contributions are observed on a daily scale. For instance, the influence of the Saint-Barthélémy Dam (point 1279 ) is still observed at the bay's scale through fast variations of the outflow.

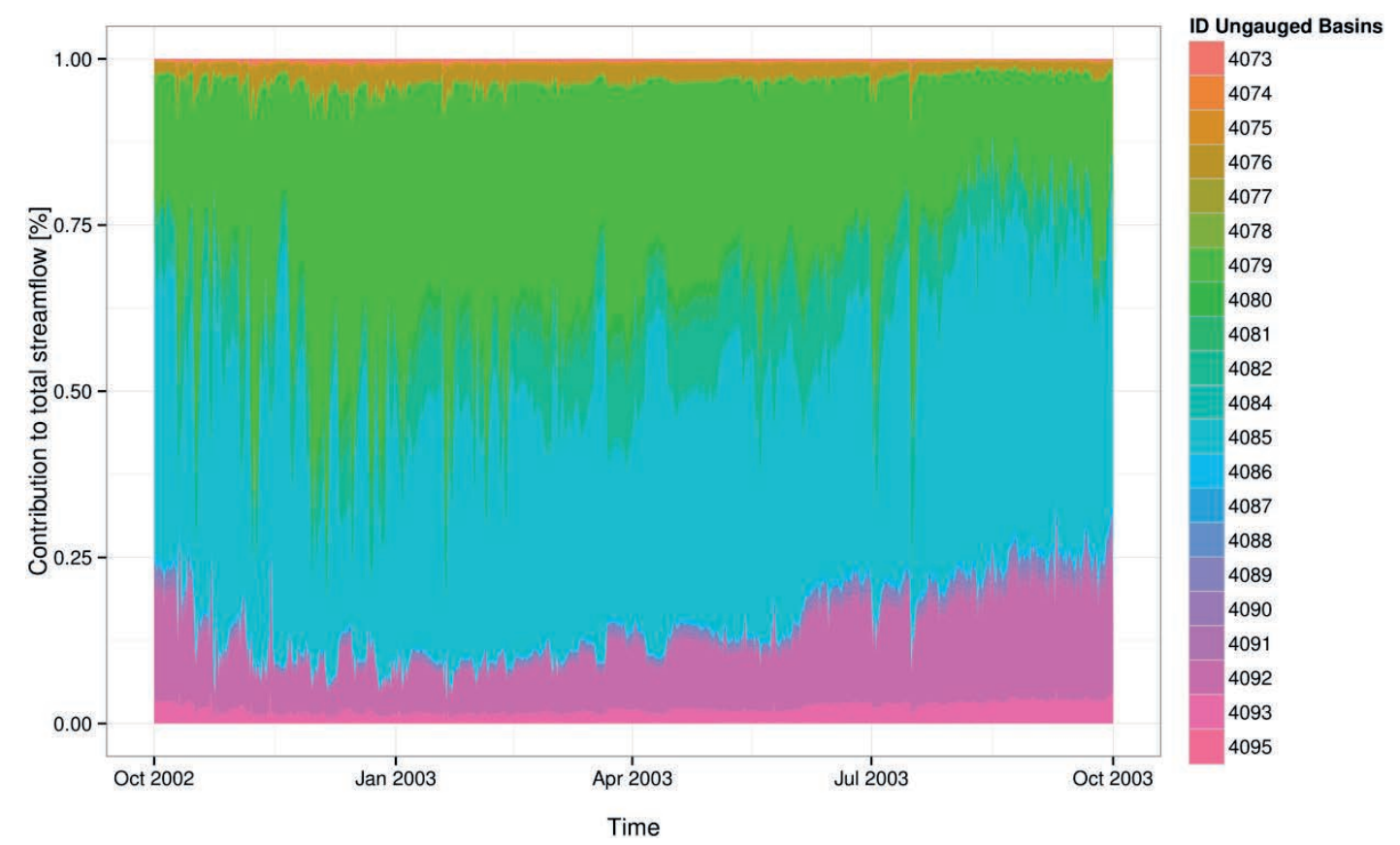

Fig. 4 Relative contributions to freshwater flowing into the bay of Saint-Brieuc at an hourly time step.

\section{CONCLUSION}

This study aimed to simulate the total outflow of Saint-Brieuc Bay. The approach consists of hydrograph transposition from a gauged basin to an ungauged one. This transposition was made possible by benefiting from a scale independent variable, which is the net rainfall assessed through inverse modelling. The approach has proved to be practical to simulate streamflow in ungauged basins. Indeed, based on geomorphological observations and parameterization, streamflow from 21 ungauged basins has been assessed from data from five gauged basins. In this way, the approach increases the value of those different monitoring stations. Finally, unlike the classical rainfallrunoff modelling approach, the approach is capable of dealing with the influence of a dam in order to check its effect on the total outflow from the bay.

\section{REFERENCES}

Aouissi, J., et al. (2013) Joint spatial, topological and scaling analysis of river network geomorphometry. GéomorphologieRelief Processus Environnement 1, 7-16.

Beven, K. and Wood, E. F. (1993) CHANNEL NETWORK HYDROLOGY, Chapter: Flow routing and the hydrological response of channel networks, pp. 99-128, John Wiley \& Sons Ltd, Chichester, England.

Blöschl, G. and Sivapalan, M. (1995) Scale issues in hydrological modelling: A review. Hydrol. Processes 9, 251-290. 
Boudhraâ, H. (2007) Modélisation pluie-débit à base géomorphologique en milieu semi-aride rural tunisien : association d'approches directes et inverses, $\mathrm{PhD}$ Thesis, Institut National Agronomique de Tunisie à Tunis.

Boudhraâ, H., et al. (2006) Inversion d'une modélisation de type hydrogramme unitaire à base géomorphologique: interprétation physique et première mise en œuvre. IAHS Publ. 303, 391-399. IAHS Press, Wallingford, UK.

Boudhraâ, H., et al. (2009) Hydrograph transposition between basins through a geomorphology-based deconvolutionreconvolution approach. IAHS Publ. 333, 76-83. IAHS Press, Wallingford, UK.

Cudennec, C. (2000) Description mathématique de l'organisation du réseau hydrographique et modélisation hydrologique. PhD Thesis, Ecole Nationale Superieure Agronomique de Rennes.

Cudennec, C. (2007) On width function-based unit hydrographs deduced from separately random self-similar river networks and rainfall variability. Hydrol. Sci. J. 52, 230-237.

de Lavenne, A. (2013) Modélisation hydrologique à base géomorphologique de bassins versants non jaugés par régionalisation et transposition d'hydrogramme, PhD Thesis, Agrocampus Ouest Rennes.

de Lavenne, A., Boudhraâ H. and Cudennec C. (2014) Streamflow prediction in ungauged basins through geomorphologybased hydrograph transposition. Hydrol. Res. (in press).

Giannoni, F., et al. (2003) Hydrologic modeling of extreme floods using radar rainfall estimates. Adv. Water. Resour. 26, $195-203$.

Hrachowitz, M., et al. (2013). A decade of Predictions in Ungauged Basins (PUB) - a review. Hydrol. Sci. J. 58, 1198-1255.

Jasiewicz, J. and Metz, M. (2011) A new GRASS GIS toolkit for Hortonian analysis of drainage networks. Comput. Geosci. 37, $1162-1173$.

Menke, W. (1989) Geophysical Data Analysis: Discrete Inverse Theory, vol. 45, Academic Press.

Naden, P. S. (1992) Spatial variability in flood estimation for large catchments: the exploitation of channel network structure. Hydrol. Sci. J. 37, 53-71.

Nagel, D., Buffington, J. M., and Luce, C. (2011) A simple drainage enforcement procedure for estimating catchment area using DEM data, in NW GIS User Conference, Oct. 17-21 2011, Boise, Idaho.

Nasri, S., et al. (2004) Use of a geomorphological transfer function to model design floods in small hillside catchments in semiarid Tunisia. J. Hydrol. 287(1-4), 197-213.

Robinson, J. S., Sivapalan, M., and Snell, J. D. (1995) On the relative roles of hillslope processes, channel routing, and network geomorphology in the hydrologic response of natural catchments. Water Resour. Res. 31, 3089-3101.

Rodriguez, F., Cudennec, C., and Andrieu, H. (2005) Application of morphological approaches to determine unit hydrographs of urban catchments. Hydrol. Processes 19, 1021-1035.

Tarantola, A. and Valette, B. (1982) Inverse problems = quest for information, J. Geophys. 50, 150-170.

Yang, D., Herath, S., and Musiake, K. (2002) A hillslope-based hydrological model using catchment area and width functions, Hydrol. Sci. J. 47, 49-65. 